\title{
Perceived organizational support and moral distress among nurses
}

\author{
Navideh Robaee ${ }^{1}$, Foroozan Atashzadeh-Shoorideh ${ }^{2 *} \mathbb{D}^{*}$, Tahereh Ashktorab ${ }^{3}$, Ahmadreza Baghestani ${ }^{4}$ \\ and Maasoumeh Barkhordari-Sharifabad ${ }^{5}$
}

\begin{abstract}
Background: Moral distress is prevalent in the health care environment at different levels. Nurses in all roles and positions are exposed to ethically challenging conditions. Development of supportive climates in organizations may drive nurses towards coping moral distress and other related factors. This study aimed at determining the level of perceived organizational support and moral distress among nurses and investigating the relationship between the two variables.

Methods: This was a correlational-descriptive study. A total of 120 nurses were selected using random quota sampling method. A demographic questionnaire, Survey of Perceived Organizational Support, and Moral Distress Scale were used to collect the data which were analyzed using descriptive and analytical tests in SPSS20.

Results: The mean perceived organizational support was low $(2.63 \pm 0.79)$. The mean moral distress was $2.19 \pm 0.58$, which shows a high level of moral distress. Moreover, Statistical analysis showed no significant relationship between perceived organizational support and moral distress $(r=0.01, p=0.86)$.

Conclusion: Given the low level of perceived organizational support and high moral distress among nurses in this study, it is necessary to provide a supportive environment in hospitals and to consider strategies for diminishing moral distress.
\end{abstract}

Keywords: Ethics, Morals, Perceived organizational support, Moral distress, Nurses

\section{Background}

Moral distress is a common problem among the professionals employed in health care settings [1]. It occurs when the individuals feel that they cannot act according to the pivotal values and duties or when the measures taken to achieve the intended results fail to succeed so that the totality of individual's ethical principles is seriously endangered [2]. In other words, moral distress can be considered as the stress tolerated by professionals at a time when, despite an awareness of the right performance, they cannot achieve the correct performance due to some barriers [1, 3-5]. Moral distress has been described as a major problem in the nursing profession $[5,6]$.

\footnotetext{
* Correspondence: $f$ atashzadeh@sbmu.ac.ir

${ }^{2}$ Department of Nursing Management, School of Nursing and Midwifery, Shahid Beheshti University of Medical Sciences, Vali-Asr Avenue, Cross of Vali-Asr and Hashemi Rafsanjani Highway, Opposite to Rajaee Heart Hospital, Tehran 1996835119, Iran

Full list of author information is available at the end of the article
}

The particular characteristics of nursing and the different work cultures generated in different health care institutions expose nurses to a higher risk of moral distress than other professionals [7]. Moral distress has undesirable outcomes for both nurses and patients, and can have direct and indirect effects on nurses. Physical disorders such as nightmares, headache and anxiety and a dysfunctional personal life have been reported among nurses at risk for moral distress [8].

Moreover, feeling of anger, failure, sin, and disability are among the consequences of moral distress. Some studies have demonstrated that moral distress is correlated with personnel burnout, deteriorated team work, reduced quality of care, and challenges related to patient safety $[2,9,10]$. It will further lead to occupational stress and turnover [11].

Various factors contribute to moral distress in nurses among them are invasive procedures on patients with incurable diseases, orders for unnecessary tests or examinations, 
insufficient and inefficient treatment by colleagues, lack of balance in power among the health specialists, and lack of organizational support [12].

When exposed to stressful environments and high job demands, the employees need the financial and spiritual support of their organization. Perceived organizational support is a condition based on how much the organization considers employees' values and needs [13]. Organizational support is one of the important indices of nursing work environment [14], and can be considered an influential moral factor [15].

Additionally, one aspect of ethical competency of nurse leaders is their supportive behavior [14]. The leaders' supportive behavior will be compensated for by the followers' proper compliance. The organization is less likely to face a situation in which the staff's behavior disturbs the leader's or group's work [14, 16-20]. This perception of level of organizational support especially about ethical practice is a vital element of the constraints upon nurses' actions [21].

Perceived organizational support reduces stressors in the workplace and is potentially involved in dealing with work-related fatigue, excitement, and depression [22]. Supportive occupational environments are the most important factor in creating job satisfaction for nurses that influences positively the patients' treatment, absorption and maintenance of manpower in the organization. A climate with high levels of support diminishes occupational tension and maintains the nurses in the organization [23].

Moreover, some studies have revealed that perceived organizational support is negatively correlated with work absenteeism [24], and intent to turnover [25], while it is positively correlated with award expectation, role of performance and social behavior, preventive and civil behaviors [26], and also organizational commitment and subsequently self-competency [27]. Nurse leaders' supportive behavior plays a key role in productivity and promoting nurses' professional performance [20, 28].

Iran is a developing country located in the south-west of Asia with a population of about $80,000,000$ people. The nursing manpower at different levels is estimated to be about 150,000. As it is the case in many other developing countries, nurses in Iran encounter many challenges such as long working hours, changing work shifts, limited vacation, abundant occupational wants and wishes, unsatisfactory payment or salary, and inappropriate behavior towards some patients or their families [29, 30]. These challenges often result from deficient techniques of manpower management in hospitals [30], shortage of manpower, job dissatisfaction, nurses' low social status, absence of a satisfactory student acceptance system at the universities, and shortage of ethics course in the nursing curriculum [31-36], leading to increased workload, fostered medical and nursing errors, and subsequently, moral distress in nurses [36].
There are some controversies about the level of moral distress among Iranian nurses [37-40]. A review of literature related to the two variables "perceived organizational support" and "moral distress" indicated that the investigation of these two variables has been very limited on Iranian nurses. Furthermore, no comprehensive study has been found on determining the correlation between "perceived organizational support" and "moral distress" among Iranian nurses. Development of supportive organizations may lead nurses to better cope with moral distress and other problems such as job dissatisfaction [5, 21, 41-43].

\section{Aim}

The purpose of this research was to determine the level of perceived organizational support and moral distress among nurses and to investigate the relationship between these two variables.

\section{Methods \\ Research design}

This correlational descriptive study used random quota sampling to select the participants. First, considering the distribution of hospitals affiliated to Shahid Beheshti University of Medical Sciences in different regions of Tehran (north, south, east, west and center), one hospital was randomly selected from each region and the required number of nurses was selected from each hospital in proportion to the total number of nurses working in it. Considering the number of hospitals surveyed, 120 questionnaires were distributed among all the qualified nurses selected from the morning, evening, and night shifts using random sampling.

The sample size was calculated by the following formula to explore correlation between moral distress and perceived organizational support.

$$
N=\left[\frac{Z_{\alpha}+Z_{\beta}}{c}\right]^{2}+3
$$

Where $\mathrm{N}$ is the desired sample size, $Z_{\alpha}$ is the standard normal score of $95 \%$ of confidence interval $=1.96, Z_{\beta}=$ statistical power at $90 \%$, which is 1.28 and $c=0 / 5 \times$ $\operatorname{Ln}[(1+r)(1-r)]$ with being the correlation coefficient, which is 0.3 according to a study by Jay ManingoSalinas [15].

Considering a participant attrition of $10 \%, 120$ nurses were selected for the study. However, 110 completed questionnaires were analyzed. The study inclusion criteria consisted of having a bachelor's degree or higher in nursing and at least 1 year of work experience.

\section{Data collection tools}

In this study, a demographic questionnaire, Eiesenberger's Survey of Perceived Organizational Support (SPOS), and 
nurses' Moral Distress Scale (MDS) were used to collect the data.

\section{Demographic information questionnaire}

The demographic questionnaire examined participants' demographic data including age, gender, marital status, level of education, work experience, work shifts, and history of attendance in ethics workshops.

\section{Survey of Perceived Organizational Support}

The 8-item SPOS was developed by Eisenberger et al. [13]. Each item in this survey is scored based on a 7-point Likert scale from strongly disagree (zero) to strongly agree (six). The range of scores in each item varies from zero to six while on a total scale is zero to 48 . A higher score indicates more perceived organizational support. This scale is a unidimensional measure and has been widely used in research studies. Evidence of its validity and reliability has been reported in numerous studies [44-46]. The Cronbach's alpha coefficient of perceived organizational support was calculated as 0.74 in this study.

\section{Moral distress scale}

The nurses' MDS is a native scale developed by Atashzadeh-Shoorideh et al. [40]. It contains 30 items in three dimensions, namely "inappropriate competencies and responsibilities", "errors", and "not respecting the ethical principles". All the items in this scale are scored based on a 5-point Likert scale from 0 (not at all) to 4 (very much). The score of moral distress is then calculated as the mean of the total score of the items. The score of moral distress obtained is then classified into four categories: $0-1$ is low, $1.01-2$ is moderate, $2.01-3$ is high, and $3.01-4$ is very high moral distress. The Cronbach's alpha coefficient for the "Moral Distress Scale" and all of its dimensions designed by AtashzadehShoorideh et al. was calculated in this study as 0.77 .

\section{Data collection}

The participants were oriented on how to answer the questionnaires and were informed about the voluntary nature of participation in the study. The questionnaires were distributed among nurses working in different shifts and were collected within 2 days.

\section{Data analysis}

The collected data was analyzed via SPSS 20 using the descriptive statistics of data as absolute and relative frequency report, and inferential statistics as a determination of correlation between the variables under study via Pearson product moment correlation coefficient.

\section{Results}

The study participants consisted of 110 nurses with a mean age of $34.1 \pm 7.4$ years and a mean work experience of $9.6 \pm 6.5$ years, $90 \%$ of them were female, $55.5 \%$ were married and $95.5 \%$ held a bachelor's degree in nursing. The majority of the nurses $(48.2 \%)$ were working in rotating shifts. The majority $(51.8 \%)$ had not attended ethics workshops in the past (Table 1).

As shown in Table 2, the mean perceived organizational support was low $(2.63 \pm 0.79)$ and the mean moral distress was high $(2.19 \pm 0.58)$. The highest mean of moral distress pertained to the dimension of errors $(2.43 \pm 0.65)$.No relationships were observed between perceived organizational support and moral distress $(p=0.86)$ or its dimensions $(p>0.05)$; (Table 3).

There was a statistically significant relationship between moral distress and work shifts. Also, relationship between the dimension of errors and work shifts was statistically significant. The significance level set for the work shift test was $p=0.04$ for moral distress and $p=0.00$ for the dimension of errors. A significant relationship was also observed between the inappropriate competencies and responsibilities dimension of moral distress and work experience $(p=0.04)$ as shown in Table 4.

\section{Discussion}

This study was conducted to determine the level of perceived organizational support and moral distress among nurses and to investigate the relationship between these two variables.

The results revealed low perceived organizational support in the nurses, this finding supports the results of previous studies. In a study by Kwak conducted on nurses in South Korea, organizational support was investigated using corrected nursing work index with a rate assessed as falling in the low limits [47]. Another

Table 1 Sociodemographic characteristics of study participant

\begin{tabular}{|c|c|c|c|}
\hline Variables & & $M(S D)$ & n (\%) \\
\hline Age & & $34.1(7.4)$ & \\
\hline \multirow[t]{2}{*}{ Gender } & Female & & $99(90)$ \\
\hline & Male & & $11(10)$ \\
\hline \multirow[t]{2}{*}{ Marital Status } & Single & & $49(44.5)$ \\
\hline & Married & & $61(55.5)$ \\
\hline \multirow[t]{2}{*}{ Level of Education } & Bachelor's Degree & & $105(95.5)$ \\
\hline & Master's Degree & & $5(4.5)$ \\
\hline Work Experience & & $9.6(6.5)$ & \\
\hline \multirow[t]{2}{*}{ Work Shifts } & Fixed & & $35(31.8)$ \\
\hline & Rotating & & $75(68.2)$ \\
\hline \multirow{2}{*}{$\begin{array}{l}\text { History of attendance } \\
\text { in ethics workshops. }\end{array}$} & Yes & & $53(48.2)$ \\
\hline & No & & $57(51.8)$ \\
\hline
\end{tabular}


Table 2 Mean and standard deviation of perceived organizational support, moral distress, and the associated dimensions

\begin{tabular}{lll}
\hline Variable & Mean(SD) & Range of Score \\
\hline Perceived organizational support & $2.63(0.79)$ & $0.75-4.25$ \\
Total moral distress & $2.19(0.58)$ & $1-3.40$ \\
Inappropriate competencies and & $2.12(0.54)$ & $1-3.70$ \\
responsibilities & & \\
Errors & $2.43(0.65)$ & $1-3.73$ \\
Not respecting the ethical principles & $1.96(0.76)$ & $1-3.56$ \\
\hline
\end{tabular}

No relationships were observed between perceived organizational support and moral distress $(p=0.86)$ or its dimensions $(p>0.05)$; (Table 3$)$

study carried out on nurses in Italy reported the mean score of perceived organizational support as $2.26 \pm$ 0.78 which is lower than the central point value reported by Eisenberger et al.'s scale [48]. This is inconsistent with other studies that reported moderate perceived organizational support [15, 29]. Jay Maningo-Salinas investigated the perceived organizational support level among oncology nurses using Eisenberg et al.'s scale and reported it at the moderate level of $3.70 \pm$ 0.86.16. Moreover, the study by Gorji et al. reported the perceived organizational support among the emergency room nurses as moderate [29].

The dissimilarity of results between these studies and the present one may be due to the differences in the instruments used, the research populations, the climate of the organization and how their respective managers managed the research populations. The lack of a supportive environment in hospitals may cause further moral and work conflicts, job dissatisfaction, and reduced employees' trust in the organization [48].

The current study reported the intensity of moral distress as high among the nurses, which is consistent with the results obtained by Woods et al. conducted on nurses in New Zealand [49]. Also, Cummings found that the prevalence of moral distress was high among nurses and proposed this phenomenon as responsible for nurses' turnover rates [50].

Moral distress has been reported as moderate in some studies [37-39,53], while it is reported to be lower than moderate in a number of other studies [51, 52]. A study on Swedish nurses elucidated the point that moral distress was at the low range [54]. Additionally, the studies carried out in America reported the nurses' moral distress scores at rather low levels [5, 55]. Another study undertaken in Turkey showed that nurses had low-level moral distress [1], a finding which is inconsistent with our results.

This inconsistency may be attributed to differences in organizational, cultural, educational, geographical, and individual factors and beliefs. For instance, mention can be made of the existence of the required standards of care in hospitals, level of knowledge and awareness, high participation of the health staff, and ethical traits of the participants. Also, it may be speculated that the extreme differences in moral distress between this study and other endeavors may be attributed to variations in the study population and measurement instruments used in the present study. The scale used in this study to measure moral distress includes three dimensions while the moral distress instrument used in other studies has been one-dimensional with some items not appropriately working in the Iranian context. For example, the item of "discharge a patient when he has reached the maximum length of stay based on diagnostic related grouping although he has many teaching needs" in Corley Moral Distress Scale isn't appropriate in Iranian nurses. Comparing the findings of this research with other studies has shown that moral distress for most nurses is moderate to high.

In this study, the highest level of moral distress pertained to the dimension of "errors", while the lowest level belonged to the aspect of "not respecting ethical principles". In numerous studies, the most common causes of moral distress among nurses have been reported to be working with incompetent staff [1, 40, 49, $56]$, useless care $[1,40]$, and inappropriate intra-team relations $[1,49]$. On the basis of the results of these studies, high level of distress in the dimension of "errors" seems to be logical compared to other dimensions.

The results of this study showed no statistically significant relationships between perceived organizational support and moral distress and any of its' dimensions, A study by Maningo-Salinas, conducted on oncology nurses, expunged upon the correlation between moral distress and inclination for turnover and also determined the mediating effect of perceived organizational support on these two variables. Their findings suggested that perceived organizational support does not mediate the correlation between moral distress and inclination for turnover and that the interaction between moral distress and perceived organizational support was not statistically significant [15]. They point out no statistically

Table 3 Correlation between perceived organizational support and moral distress and its dimensions

\begin{tabular}{|c|c|c|c|c|c|c|c|c|}
\hline & \multicolumn{2}{|c|}{ Inappropriate competencies and responsibilities } & \multicolumn{2}{|l|}{ Errors } & \multicolumn{2}{|c|}{ No respect for ethics } & \multicolumn{2}{|c|}{ Total moral distress } \\
\hline & $r$ & $\mathrm{p}$ & r & $p$ & $r$ & $p$ & r & $p$ \\
\hline Perceived organizational support & 0.048 & 0.61 & 0.062 & 0.52 & -0.062 & 0.52 & 0.017 & 0.86 \\
\hline
\end{tabular}


Table 4 Correlation between organizational support and moral distress and its dimensions with Sociodemographic characteristics

\begin{tabular}{|c|c|c|c|c|c|c|c|c|c|c|c|}
\hline \multirow[t]{2}{*}{ Variable } & & \multicolumn{2}{|c|}{$\begin{array}{l}\text { Perceived organizational } \\
\text { support }\end{array}$} & \multicolumn{2}{|c|}{ Total moral distress } & \multicolumn{2}{|c|}{$\begin{array}{l}\text { Inappropriate competencies } \\
\text { and responsibilities }\end{array}$} & \multicolumn{2}{|l|}{ Errors } & \multicolumn{2}{|c|}{$\begin{array}{l}\text { Not respecting the } \\
\text { ethical principles }\end{array}$} \\
\hline & & $r$ & $p$ & $r$ & $p$ & $r$ & $p$ & $r$ & $p$ & $r$ & $p$ \\
\hline Age & & -0.10 & 0.25 & -0.04 & 0.67 & 0.12 & 0.20 & -0.17 & 0.07 & 0.00 & 1.00 \\
\hline \multirow[t]{2}{*}{ Gender } & Female & 0.01 & 0.89 & 0.06 & 0.51 & 0.07 & 0.43 & 0.06 & 0.54 & -0.03 & 0.70 \\
\hline & Male & & & & & & & & & & \\
\hline \multirow[t]{2}{*}{ Marital Status } & Single & 0.07 & 0.42 & -0.07 & 0.42 & 0.08 & 0.40 & -0.17 & 0.06 & -0.01 & 0.86 \\
\hline & Married & & & & & & & & & & \\
\hline \multirow[t]{2}{*}{ Level of Education } & Bachelor's Degree & 0.10 & 0.27 & 0.10 & 0.28 & 0.18 & 0.06 & 0.08 & 0.40 & 0.76 & 0.43 \\
\hline & Master's Degree & & & & & & & & & & \\
\hline Work Experience & & -0.14 & 0.12 & 0.00 & 0.98 & 0.19 & $0.04^{*}$ & -0.14 & 0.13 & 0.00 & 0.95 \\
\hline \multirow[t]{2}{*}{ Work Shifts } & Fixed & 0.07 & 0.44 & 0.18 & $0.04^{*}$ & 0.07 & 0.41 & 0.25 & $0.00^{*}$ & 0.13 & 0.15 \\
\hline & Rotating & & & & & & & & & & \\
\hline
\end{tabular}

significant relationship, this possibility suggests that Eisenberg's perceived organizational support scale may not be the best instrument for measuring perceived organizational support among the nurses. Hence, it is necessary to carry out a more comprehensive study regarding the use of a perceived organizational support tool in nursing [15].

Of course, several studies have reported the effect of ethical work climate on moral distress. The ethical climate does not often lead to personnel's' perceived organizational support. The reason for this can be the creation of a work environment which is reliable in the organization [57]. Fogel showed that ethical climate agents have a moderating effect on the moral distress, turnover, poor patient care, and justice subjects [58]. In the study by Fogel, the relations between managers and Fnurses induced significant effects on ethical work climate [58]. This, in turn, affects moral distress. Silen's study showed that ethical climate is an important factor in nurses' work setting [54]. But in some articles, it has been indicated that a negative relationship exists between ethical climate and moral distress [50-53, 59].

In the current study, perceived organizational support was not significantly correlated with any of the demographic variables examined, while a significant relationship was observed between the inappropriate competencies and responsibilities dimension of moral distress and the variable of work experience. The present study found a statistically significant relationship between total moral distress and the dimension of errors and work shifts. This is inconsistent with the results obtained by Atashzadeh-Shoorideh et al. [40]. The inconsistency between the findings of the present study and the study of Atashzadeh-Shoorideh et al. may be due to the differences in the research setting and work environment, which may have led to lower rates of error and moral distress in the nurses examined by AtashzadehShoorideh et al. [40].

The limitations of this research are the descriptive design and data collection with a questionnaire and reliance on self-report data. As a result, some people may refuse to provide real responses and give unrealistic responses. A further limitation is the potential impact of confounding factors such as high occupancy, fatigue, and lack of readiness of nurses to complete the questionnaire. This study used a cross-sectional design. For this reason, it makes the conclusion about cause-effect relations difficult. Therefore, a closer examination can be done by conducting indepth and longitudinal studies. A further limitation of this research was the selection of nurses from just one city. With the implementation of national and international studies, the possibility of generalizing these findings will increase.

\section{Conclusion}

The results of this study showed that the level of perceived organizational support was low in nurses and moral distress was high. Therefore, it is necessary to provide a supportive environment in hospitals and to consider strategies for diminishing moral distress.

Also, the findings indicated that there was no significant correlation between perceived organizational support and moral distress. These results are not consistent with the findings of other studies on moral distress. It is recommended that a similar study be carried out with other measurement scales of organizational support and the results be compared and contrasted with our findings.

\section{Abbreviations}

ICU: Intensive Care Unit; MDS: Moral Distress Scale; RN: Registered Nurse; SPOS: Survey of Perceived Organizational Support 


\section{Acknowledgments}

The authors would like to express their gratitude to all the hospitals affiliated to the Ministry of Health and its medical sciences universities, to all the participating nurses and finally to Dr. Eisenberger for allowing us to use the Survey of Perceived organizational support.

\section{Funding}

This research project was funded by Shahid Beheshti University of Medical Sciences in Tehran, Iran (Project code: 7582). Shahid Beheshti University of Medical Sciences had no part in the design of the study and collection, analysis, and interpretation of data and in writing the manuscript.

\section{Availability of data and materials}

Sharing the data is not possible due to an agreement with the participants on the confidentiality of the data.

\section{Authors' contributions}

All authors (NR, FA, TA, AB and MB) have participated in the conception and design of the study. NR contributed the data collection and prepared the first draft of the manuscript. FA and TA critically revised and checked closely the proposal, the analysis and interpretation of the data and design the article. $A B$ carried out the analysis, interpretation of the data and drafting the manuscript. $M B$ has been involved in revising the manuscript critically. All authors read and approved the final manuscript.

\section{Ethics approval and consent to participate}

This study was approved by the Ethics Committee of Shahid Beheshti University of Medical Sciences (No. 1394.255). The questionnaires were distributed among the participants after obtaining legal permissions from the authorities and ensuring compliance with ethical issues. Before commencing the study, written consent was provided by all participants. Permissions to use the SPOS and the MDS were obtained from instruments developers.

\section{Consent for publication}

The article does not contain any individual's details and consent for publication is not applicable.

\section{Competing interests}

The authors declare that they have no competing interests.

\section{Publisher's Note}

Springer Nature remains neutral with regard to jurisdictional claims in published maps and institutional affiliations.

\section{Author details \\ ${ }^{1}$ Student Research Committee of Nursing and Midwifery, International Branch of Shahid Beheshti University of Medical Sciences, Tehran, Iran. 2Department of Nursing Management, School of Nursing and Midwifery, Shahid Beheshti University of Medical Sciences, Vali-Asr Avenue, Cross of Vali-Asr and Hashemi Rafsanjani Highway, Opposite to Rajaee Heart Hospital, Tehran 1996835119, Iran. ${ }^{3}$ School of Nursing and Midwifery, Shahid Beheshti University of Medical Sciences, Tehran, Iran. ${ }^{4}$ Department of Biostatistics, School of Allied Medical Sciences, Shahid Beheshti University of Medical Sciences, Tehran, Iran. ${ }^{5}$ Department of Nursing, School of Medical Science, Yazd Branch, Islamic Azad University, Yazd, Iran.}

Received: 30 July 2017 Accepted: 18 December 2017

Published online: 10 January 2018

\section{References}

1. Karagozoglu S, Yildirim G, Ozden D, Çınar Z. Moral distress in Turkish intensive care nurses. Nurs Ethics. 2017:24(2):209-24.

2. Wallis L. Moral distress in nursing. AJN Am J Nurs. 2015;115(3):19-20.

3. Johnstone $\mathrm{M}-\mathrm{J}$, Hutchinson A. "Moral distress"-time to abandon a flawed nursing construct? Nurs Ethics. 2015;22(1):5-14.

4. McCarthy J, Gastmans C. Moral distress: a review of the argument-based nursing ethics literature. Nurs Ethics. 2015;22(1):131-52.

5. Corley MC, Minick P, Elswick RK, Jacobs M. Nurse moral distress and ethical work environment. Nurs Ethics. 2005;12(4):381-90.
6. Gallagher A. Moral distress and moral courage in everyday nursing practice. Online J Issues Nurs. 2011;16(2):1-8.

7. Hamric $A B$, Borchers $C T$, Epstein EG. Development and testing of an instrument to measure moral distress in healthcare professionals. AJOB Prim Res. 2012;3(2):1-9.

8. Lazzarin M, Biondi A, Di Mauro S. Moral distress in nurses in oncology and haematology units. Nurs Ethics. 2012;19(2):183-95.

9. Rodney PA. What we know about moral distress. AJN Am J Nurs. 2017; 117(2):S7-10.

10. Burston AS, Tuckett AG. Moral distress in nursing: contributing factors, outcomes and interventions. Nurs Ethics. 2013;20(3):312-24.

11. Corley MC, Elswick RK, Gorman M, Clor T. Development and evaluation of a moral distress scale. J Adv Nurs. 2001:33(2):250-6.

12. McCarthy J, Deady R. Moral distress reconsidered. Nurs Ethics. 2008;15(2): 254-62.

13. Eisenberger $\mathrm{R}$, Jones JR, Aselage J, Sucharski IL. Perceived organizational support. J Appl Psychol. 1986;71(3):500-7.

14. Barkhordari-Sharifabad M, Ashktorab T, Atashzadeh-Shoorideh F. Ethical competency of nurse leaders A qualitative study. Nurs Ethics. 2016; Epub ahead of print 14 Jun 2016. DOI: https://doi.org/10.1177/0969733016652125.

15. Maningo-Salinas MJ. Relationship between moral distress, perceived organizational support and intent to turnover among oncology nurses. Minneapolis, MN: Capella University; 2010.

16. Den Hartog DN, De Hoogh AHB. Empowering behaviour and leader fairness and integrity: studying perceptions of ethical leader behaviour from a levels-of-analysis perspective. Eur J Work Organ Psychol. 2009; 18(2):199-230.

17. Mayer DM, Kuenzi M, Greenbaum R, Bardes M, Salvador RB. How low does ethical leadership flow? Test of a trickle-down model. Organ Behav Hum Decis Process. 2009:108:1-13.

18. Neubert MJ, Carlson DS, Kacmar KM, Roberts JA, Chonko LB. The virtuous influence of ethical leadership behavior: evidence from the field. J Bus Ethics. 2009;90(2):157-70

19. Resick CJ, Hanges PJ, Dickson MW, Mitchelson JK. A cross-cultural examination of the endorsement of ethical leadership. J Bus Ethics. 2006;63(4):345-59.

20. Barkhordari-Sharifabad M, Ashktorab T, Atashzadeh-Shoorideh F. Ethical leadership outcomes in nursing: A qualitative study. Nurs Ethics. 2017; Epub ahead of print 18 Jan 2017. doi: https://doi.org/10.1177/0969733016687157.

21. Erlen JA. Moral distress: a pervasive problem. Orthop Nurs. 2001;20(2):76-80.

22. Liu L, Hu S, Wang L, Sui G, Ma L. Positive resources for combating depressive symptoms among Chinese male correctional officers: perceived organizational support and psychological capital. BMC Psychiatry. 2013;13:89.

23. AbuAlRub RF. Job stress, job performance, and social support among hospital nurses. J Nurs Scholarsh. 2004;36(1):73-8.

24. Adebayo SO, Nwabuoku UC. Conscientiousness and perceived organizational support as predictors of employee absenteeism. Park J Soc Sci. 2008;5(4):363-7.

25. Tumwesigye $\mathrm{G}$. The relationship between perceived organisational support and turnover intentions in a developing country: the mediating role of organisational commitment. African J Bus Manag. 2010:4(6):942-52.

26. Uymaz AO. Prosocial organizational behavior: is it a personal trait or an organizational one. Eur J Bus Manag. 2014;6(2):124-9.

27. Battistelli A, Galletta M, Vandenberghe C, Odoardi C. Perceived organisational support, organisational commitment and self-competence among nurses: a study in two Italian hospitals. J Nurs Manag. 2016;24(1):E44-53.

28. Dehghan Nayeri N, Nazari AA, Salsali M, Ahmadi F, Adib HM. Iranian staff nurses' views of their productivity and management factors improving and impeding it: a qualitative study. Nurs Health Sci. 2006:8(1):51-6.

29. Gorji HA, Etemadi M, Hoseini F. Perceived organizational support and job involvement in the Iranian health care system: a case study of emergency room nurses in general hospitals. J Educ Health Promot. 2014;3:58.

30. Sabokroo M, Kalhorian R, Kamjoo Z, Taleghani G. Work-family conflict: the role of organizational support on intention to leave the job (case study of Tehran hospital nurses). J Public Manag. 2011:3(6):111-26.

31. Shahriari M, Mohammadi E, Abbaszadeh A, Bahrami M, Fooladi MM. Perceived ethical values by Iranian nurses. Nurs Ethics. 2011;19(1):30-44.

32. Esmaelzadeh F, Abbaszadeh A, Borhani F, Peyrovi $\mathrm{H}$. Ethical sensitivity in nursing ethical leadership: a content analysis of Iranian nurses experiences. Open Nurs J. 2017;11:1-13.

33. Atashzadeh-Shorideh F, Ashktorab T, Yaghmaei F. Iranian intensive care unit nurses' moral distress a content analysis. Nurs Ethics. 2012;19(4):464-78. 
34. Farsi Z, Dehghan Nayeri N, Negarandeh R, Broomand S. Nursing profession in Iran: an overview of opportunities and challenges. Japan J Nurs Sci 2010; 7(1):9-18.

35. Sadeghi A, Goharloo Arkawaz A, Cheraghi F, Moghimbeigi A. Relationship between head nurses' servant leadership style and nurses' job satisfaction. Q J Nurs Manag. 2015:4(1):28-38.

36. Cheraghi MA, Salsali M, Safari M. Ambiguity in knowledge transfer: the role of theory-practice gap. Iran J Nurs Midwifery Res. 2010;15(4):155-66.

37. Poladi F, Atashzadeh-Shoorideh F, Abaaszade A, Moslemi A. The correlation between moral distress and burnout in nurses working in educational hospitals of Shahid Beheshti University of Medical Sciences during 2013. Iran J Med Ethics Hist Med. 2015;8(4):37-45.

38. Joolaee $\mathrm{S}$, Jalili $H$, Rafiee $F$, Haggani $H$. The relationship between nurses' perception of moral distress and ethical environment in Tehran University of Medical Sciences. Iran J Med Ethics Hist Med. 2011:4(4):56-66.

39. Ameri M, SafaviBayat Z, Ashktorab T, Kavoosi A. Atefeh Vaezi. Moral distress: evaluating nurses' experiences. Iran J Med Ethics Hist Med. 2013;6(1):64-73.

40. Atashzadeh-Shoorideh F, Ashktorab T, Yaghmaei F, Alavi MH. Relationship between ICU nurses' moral distress with burnout and anticipated turnover. Nurs Ethics. 2015;22(1):64-76.

41. Cassells JM, Silva MC, Chop RM. Administrative strategies to support staff nurses as moral agents in clinical practice. Nursingconnections. 1990;3(4):31-7.

42. Corley MC. Nurse moral distress: a proposed theory and research agenda. Nurs Ethics. 2002;9(6):636-50

43. Olson LL. Ethical climate as the context for nursing retention. J Illinois Nurs. 2002;99(6):3-7.

44. Lee J, Peccei R. Discriminant validity and interaction between perceived organizational support and perceptions of organizational politics: a temporal analysis. J Occup Organ Psychol. 2011;84(4):686-702.

45. Francis CA. The mediating force of "face" supervisor character and status related to perceived organizational support and work outcomes. J Leadersh Organ Stud. 2012;19(1):58-67.

46. Gillet N, Colombat P, Michinov E, Pronost A, Fouquereau E. Procedural justice, supervisor autonomy support, work satisfaction, organizational identification and job performance: the mediating role of need satisfaction and perceived organizational support. J Adv Nurs. 2013;69(11):2560-71.

47. Kwak C, Chung BY, Xu Y, Eun-Jung C. Relationship of job satisfaction with perceived organizational support and quality of care among south Korean nurses: a questionnaire survey. Int J Nurs Stud. 2010;47(10):1292-8.

48. Bobbio A, Bellan M, Manganelli AM. Empowering leadership, perceived organizational support, trust, and job burnout for nurses: a study in an Italian general hospital. Health Care Manag Rev. 2012;37(1):77-87.

49. Woods M, Rodgers $V$, Towers A, La Grow S. Researching moral distress among New Zealand nurses: a national survey. Nurs Ethics. 2015;22(1):117-30.

50. Cummings $\mathrm{CL}$. The effect of moral distress on nursing retention in the acute care setting. Jacksonville, FL:University of North Florida; 2009.

51. Maiden JM. A quantitative and qualitative inquiry into moral distress, compassion fatigue, and medication error in critical care nurses. San Diego, CA: University of San Diego; 2008

52. Fernandez-Parsons R, Rodriguez L, Goyal D. Moral distress in emergency nurses. J Emerg Nurs. 2013;39(6):547-52.

53. Pauly B, Varcoe C, Storch J, Newton L. Registered nurses' perceptions of moral distress and ethical climate. Nurs Ethics. 2009;16(5):561-73.

54. Silén M, Svantesson M, Kjellström S, Sidenvall B, Christensson L. Moral distress and ethical climate in a Swedish nursing context: perceptions and instrument usability. J Clin Nurs. 2011;20(23-24):3483-93.

55. O'Connell CB. Gender and the experience of moral distress in critical care nurses. Nurs Ethics. 2015;22(1):32-42.

56. Vaziri MH, Merghati-Khoei $\mathrm{E}$, Tabatabaei S. Moral distress among Iranian nurses. Iran J Psychiatry. 2015;10(1):32-6.

57. Valentine S, Greller MM, Richtermeyer SB. Employee job response as a function of ethical context and perceived organization support. J Bus Res. 2006;59(5):582-8.

58. Fogel KM. The relationships of moral distress, ethical climate, and intent to turnover among critical care nurses. Chicago, IL: The University of Chicago; 2007.

59. Mathumbu D, Dodd N. Perceived organisational support, work engagement and organisational citizenship behaviour of nurses at Victoria Hospital. Aust J Psychol. 2013;4(2):87-93.

\section{Submit your next manuscript to BioMed Central and we will help you at every step:}

- We accept pre-submission inquiries

- Our selector tool helps you to find the most relevant journal

- We provide round the clock customer support

- Convenient online submission

- Thorough peer review

- Inclusion in PubMed and all major indexing services

- Maximum visibility for your research

Submit your manuscript at www.biomedcentral.com/submit
C) Biomed Central 